\title{
ANALISIS BAHAYA KERUSAKAN FUNGSI DAS CIMANUK HULU BERDBASIS DAYA DUKUNG
}

\author{
Dwi Rahayu Susanti 1) , Boedi Tjahjono2), Yayat Hidayat ${ }^{3)}$ \\ ${ }^{1}$ Program StudiTeknik Lingkungan, Fakultas TeknikUniversitas Hamzanwadi \\ 2,3 Departemen Ilmu Tanah dan Sumberdaya Lahan, Fakultas Pertanian, IPB \\ Email: nengdwirahayu@gmail.com
}

\begin{abstract}
ABSTRAK
Tujuan penelitian ini adalah, untuk menentukan daya dukung jasa ekosistem penyediaan pangan, pengaturan tata air dan analisis kerusakan fungsi DAS Cimanuk Hulu, menggunakan metode AHP dan MCE. Daya dukung jasa ekosistem penyediaan pangan tahun 1995-2015 mengalami peningkatan luas. Pada tahun 1995 luas lahan rendah seluas $9.188 \mathrm{Ha}$, tahun 2005 seluas 4.814 dan tahun 2015 seluas $4.940 \mathrm{Ha}$. Luas lahan berpotensi sedang pada tahun 1995 sekitar 56.248 Ha, tahun 2005 seluas 45.400 dan tahun 2015 seluas 44.651. Luasan penurunan lahan sedang dari tahun 1995-2005 seluas 10.894 Ha, tahun 2005-2015 seluas 748 Ha. Luasan lahan berpotensi tinggi mengalami peningkatan, tahun 1995 seluas 52.132 Ha, tahun 2005 seluas 67.360 Ha dan tahun 2015 seluas 44.651. Daya dukung jasa ekosistem pengtauran tata air dari tahun 1995-2015 mengalami penurunan luasan, pada tahun 1995, luas lahan rendah seluas 15.551, kemudian pada tahun 2005 seluas 27.759 dan pada tahun 2015 seluas 31.225 Ha. Luasan lahan berpotensi sedang pada tahun 1995 sekitar 41.158 Ha, tahun 2005 seluas 53.044 dan untuk tahun 2015 seluas 51.390 Ha. Lahan berpotensi tinggi mengalami penurunan dari tahun 1995 seluas 52.132 Ha, sedangkan tahun 2005 seluas 67.360 Ha dan pada tahun 2015 seluas 44.651. pada penelitian ini diperoleh bahwa terjadi penurunan dayadukung pengaturan tata air, akibatnya DAS mengalami kerusakan fungsi. Hal ini disebabkan oleh perubahan penggunaan lahan sebagai areal pertanian pangan. , setidaknya dari tahun 1995 hingga 2015, telah berdampak buruk dengan menurunnya daya dukung tata air DAS hulu, atau dengan kata lain telah merusak fungsi DAS sebagai daerah tangkapan air.
\end{abstract}

Kata Kunci:Daya dukung lingkungan, kerusakan fungsi DAS, Cimanuk Hulu

\section{PENDAHULUAN}

Fungsi Pokok DAS Cimanuk Hulu adalah sebagai daerah konservasi tanah dan air (Menteri Pekerjaan Umum 2010), sehingga berperan penting untuk menyerap dan menyimpan air ke dalam tanah. Oleh karena itu tutupan lahan berupa hutan harus tetap terjaga, karena jika penggunaan lahan berubah maka dapat mempengaruhi kondisi tata airnya, sehingga hal ini dapat menimbulkan berbagai macam bencana baik di wilayah itu sendiri maupun di wilayah hilirnya.

Daya dukung suatu DAS dapat diartikan sebagai kemampuan DAS untuk mewujudkan kelestarian dan keserasian ekosistem serta meningkatnya manfaat sumberdaya 
alam yang menunjang kehidupan di dalamnya secara berkelanjutan. Daya dukung suatu DAS mempunyai peranan penting agar proses pembangunan yang dilaksanakan dapat berkelanjutan. Dalam praktiknya, upaya pemanfaatan sumberdaya alam untuk kegiatan pembangunan sebaiknya memperhatikan kondisi lingkungannya (Soemarwoto 1984 dalam Adi dan Savitri 2017).

Suatu kondisi yang menunjukkan berkurangnya daya dukung suatu lingkungan adalah kejadian banjir bandang pada bulan September 2016 di Kota Garut. Namun menilik sejarahnya, ternyata selain tahun 2016, banjir bandang pernah terjadi pada tahun-tahun sebelumnya, yaitu pada tahun 2011 dan tahun 2014 (Nugraha 2016).

Kejadian bencana tidak hanya menimpa daerah hulu DAS Cimanuk, namun juga di daerah hilir yang masuk dalam wilayah Kabupaten Indramayu, yaitu sering terjadi kekeringan pada musim kemarau dan banjir pada musim penghujan sehingga menyebabkan gagal panen. Padahal wilayah ini telah ditetapkan sebagai lumbung padi lokal maupun nasional. Buruknya respon hidrologi DAS banyak disebabkan oleh perubahan penggunaan lahan.

Perubahan penggunaan lahan diperkirakan telah banyak meningkatkan fluktuasi debit aliran sungai dan sedimentasi pada sub DAS Cimanuk Hulu (Rahman 2016; Abdurrahman 2009; Susetyaningsih 2012). Penelitian Duitasari (2016) di sub DAS Cimanuk Hulu menunjukkan bahwa perubahan luas hutan dan sawah selama 20 tahun terakhir (1995-2015) menurun drastis, sedangkan tegalan dan permukiman meningkat secara tajam. Padahal hutan diketahui memilki peran penting untuk tata air di dalam DAS (Junaidi dan Tarigan 2011). Dengan menurunnya luasan hutan maka aliran permukaan menjadi meningkat untuk dibawa keluar DAS dan berakibat pada penurunan ketersediaan air di musim kemarau (Hidayat et al. 2008). Dengan kata lainhutan mempunyai jasa ekosistem yang baik untuk tata air dan dapat mencerminkan nilai dayadukunglingkunganuntuk tata air.Jasa ekosistem adalah barang atau jasa yang di sediakan oleh ekosistem untuk manusia dan menjadi dasar untuk penilaian (valuation) suatu ekosistem (Hein et al. 2006). Ekosistem yang tertata dengan baik akan mengurangi bahaya kerusakan lingkungan dan bencana bagi manusia.

Di sisi lain penggunaan lahan yang tidak sesuai dengan daya dukung adalah faktor pendorong terjadinya degradasi lahan yang pada gilirannya menurunkan fungsi hidrologi DAS untuk mengendalikan debit aliran permukaan (Hidayat et al. 2013). MenurutTjahjonoet al. (2016) persoalanpersoalantersebutmerupakanbentukr esponnegatifdarikomponen-

komponen DAS terhadapkondisicurahhujan, dimanakuatataulemahnyaresponsang atdipengaruhi oleh karakteristikDAS baiksecarafisik, sosialekonomi,sertabudayamasyaraka tnya.

Adapun penelitian ini bertujuan untuk menganalisis dan memetakan perubahan daya dukung tata Air pada DAS Cimanuk Hulu berdasarkan daya dukung jasa ekosistem penyediaan pangan dan pengaturan tata air. Selain itu juga ditujukan untuk mengalisis 
bahaya kerusakan Fungsi DAS Cimanuk Hulu.

\section{METODE PENELITIAN}

Penelitian ini dimulai dari bulan Maret 2017 hingga Desember 2017 berlokasi di DAS Cimanuk Hulu yang terletak di Kabupaten Garut dan mempunyai luas sebesar 117,574 Ha.

Data yang digunakan dalam penelitian ini berupa data primer dan data sekunder. Data primer berupa hasil wawancara kepada expert dengan menggunakan kuesioner semantik diferensial. Data sekunder (Tabel 1) berupa data penggunaan lahan tahun 1995, 2005, 2015, dan data faset lahan. Data ini akan digunakan sebagai bahan pertanyaan pada kuesioner.

Tabel 1. Data sekunder penelitian

\begin{tabular}{clll}
\hline No & Data dan Peta & skala & Sumber \\
\hline 1 & $\begin{array}{l}\text { Penggunaan } \\
\text { lahan }\end{array}$ & $\begin{array}{l}1: \\
250.000\end{array}$ & $\begin{array}{l}\text { Duitasa } \\
\text { ri } \\
(2016)\end{array}$ \\
& & & Taufik \\
2 & Faset lahan: & $1:$ & Wiguna \\
& a. Material & 250.000 & \\
b. Relief & & \\
c. Kedalama & & \\
n & & \\
nelapuka & & \\
n batuan & & DEM \\
& Kemiringan & $1:$ & SRTM \\
& Lereng & 250.000 & $90 \mathrm{~m}$
\end{tabular}

\footnotetext{
Penilaian daya dukung dalam penelitian dilakukan dengan menggunakan daya dukung berbasis jasa ekosistem penyediaan pangan dan jasa ekosistem pengaturan tata air dengan menggunakan pendekatan bentanglahan yaitu dengan menggunakan satuan sub-faset lahan
}

sebagai satuan analisis atau satuan pemetaan. Satuan pemetaan ini dihasilkan dari gabungan antara peta faset lahan dan peta penggunaan lahan. Untuk mendapatkan nilai daya dukung dalam penelitian ini menggunakan metode Analytical Hierarchy Process (AHP) yang dikembangkan oleh Saaty (1990) dan dengan menggunakan metode Multi Criteria Evaluation (MCE).

\section{Multi Criteria Evaluation (MCE)}

MCE (Multi Criteria Evaluation) dilakuan untuk mendapatkan skor, bobot, dan nilai. Selanjutnya diolah dengan menggunakan ArcGIS 10.2, sehingga diperoleh daerah mana saja yang

mempunyaidayadukungterendahhing gatertinggidengan menggunakan rumusan berikut:

$$
\begin{aligned}
\mathrm{DDL} & =\Sigma \mathrm{FL}\{\mathrm{W}(\mathrm{M})+\mathrm{W}(\mathrm{R})+\mathrm{W}(\mathrm{KL}) \\
& +\mathrm{W}(\mathrm{KPB})\}+\{\Sigma \mathrm{W}(\mathrm{PL})\}
\end{aligned}
$$

Keterangan: DDL adalah daya dukung lingkungan, FL adalah Faset Lahan (FL) yang terdiri dari bobot material (M), bobot Relief (R), bobot Kemiringan Lereng (KL), bobot kedalaman pelapukan batuan (KPB), dan bobot penggunaan lahan (PL)

Untuk menentukan kelas nilai daya dukung lingkungan dalam tiga kelas (rendah, sedang, dan tinggi), maka diperlukan nilai interval dengan rumusan sebagai berikut (Ikqra2012)

$$
\text { Interval Kelas }=\frac{\text { Nilai Tertinggi }- \text { Nilai Terendah }}{\text { Jumlah Kelas yang dinginkan }}
$$




\section{HASIL DAN PEMBAHASAN}

Berdasarkan hasil analisis AHP (pendapat expert) didapatkan bahwa dari dua indikator yang dipilih untuk penilaian daya dukung (faset lahan dan penggunaan lahan), besarnya bobot yang berpengaruh dalam penilaian daya dukung lingkungan berbasis jasa ekosistem adalah 67\% untuk faset lahan dan 33\% untuk penggunaan lahan (Tabel 2).

Tabel 2. Skor dan bobot daya dukung lingkungan jasa ekosistem penyediaan

\begin{tabular}{lccc}
\multicolumn{4}{c}{ pangan } \\
\hline Parameter & Urutan & $\mathbf{N - R j + 1}$ & Bobot WJ \\
\hline Faset Lahan & 1 & 2 & 0,67 \\
$\begin{array}{l}\text { Penggunaan } \\
\text { Lahan }\end{array}$ & 2 & 1 & 0,33 \\
\hline Jumlah & & & \\
\hline
\end{tabular}

\section{Daya Dukung Penyediaan Pangan}

Dari sisi faset lahan, kemiringan lereng dinilai oleh paraahli sebagai komponen yang paling penting untuk penyediaan pangan, sedangkan dari sisi penggunaan lahan sawah adalah komponen yang paling penting (Tabel 3). Adapun Tabel 4 berikut menyajikan hasil penilaian terhadap komponen-komponen faset lahan.

\section{Perubahan Daya Dukung Lingkungan untuk Penyediaan Pangan}

Hasil analisis spasial daya dukung penyediaan pangan disajikan pada Gambar 2. Pada Gambar 2a (tahun 1995) terlihat bahwa kelas daya dukung tinggi (36.288 ha) terletak pada bentanglahan dataran alluvial dan dataran fluvio-vulkanik yang memiliki kemiringan lereng 0$15 \%$. Sementara itu kelas daya dukung sedang (47.808 ha) lebih banyak tersebar pada bentanglahan perbukitan atau lereng bawah kerucut vulkanik, serta kompleks Gunungapi Guntur. Pada bentanglahan tersebut penggunaan lahan yang dominan adalah hutan. Adapun untuk kelas daya dukung rendah (33.471 ha) tersebar pada bentanglahan kompleks Gunungapi Guntur dan lereng atas kerucut vulkanik dengan jenis penggunaan lahannya dominan berupa hutan dan lahan terbuka.

Gambar 2b (tahun 2005) terlihat bahwa pola persebaran kelas daya dukung untuk penyediaan pangan masih mirip dengan tahun 1995, hanya saja luasan kelas daya dukung tinggi dari tahun 1995-2005 semakin bertambah seluas 1.956 ha atau 5\%. Untuk kelas daya dukung sedang juga mengalami peningkatan luas dari tahun 1995-2005, sebesar 7.688 ha atau $16 \%$, di mana penambahan luasanya hingga lereng tengah dan lereng atas setiap bentanglahan. Sementara itu untuk kelas daya dukung rendah mengalami penurunan luasan, yaitu sebesar 8.072 ha atau 24\%. Untuk Gambar 2c (tahun 2015) terlihat bahwa pola persebaran kelas daya dukung juga masih mirip dengan tahun 1995 dan 2005 namun yang berubah adalah luasannya. Kelas daya dukung tinggi berkurang luasannya sebesar 687 ha atau $2 \%$ dengan penggunaan lahan yang dominan adalah sawah, perkebunan, dan tegalan. Sementara itu, untuk 
kelas daya dukung sedang mengalami peningkatan luas sebesar 2.592 ha atau $5 \%$ dengan jenis penggunaan lahan yang dominan berupa tegalan. Adapun untuk kelas daya dukung rendah luasannya berkurang sebesar
1.907 ha dari tahun 2005-2015, masih terdapat di kompleks Gunungapi Guntur dan di puncak Gunungapi Papandayan; penggunaan lahan dominan berupa lahan terbuka atau padang rumput.

Tabel 3. Bobot, skor, dan nilai daya dukung jasa ekositem penyediaan pangan

\begin{tabular}{lrrr}
\hline \multicolumn{1}{c}{ Parameter } & Bobot & Skor & Nilai \\
\hline Faset Lahan & $\mathbf{0 , 6 7}$ & & 0,268 \\
Kemiringan Lereng & & 0,4 & 0,201 \\
Relief & & 0,3 & 0,134 \\
Material & & 0,2 & 0,067 \\
Kedalaman Pelapukan Batuan & $\mathbf{0 , 3 3}$ & 0,1 & \\
Penggunaan Lahan & & & 0,066 \\
Sawah & & 0,20 & 0,059 \\
Tegalan & & 0,18 & 0,051 \\
Badan Air & & 0,16 & 0,044 \\
Kebun Campuran & & 0,13 & 0,037 \\
Hutan & & 0,11 & 0,029 \\
Perkebunan & 0,09 & 0,022 \\
Padang Rumput & 0,07 & 0,015 \\
Permukiman & 0,04 & 0,007 \\
Lahan Terbuka & 0,02 & \\
\hline
\end{tabular}

Tabel 4. Bobot, skor dan nilai daya dukung jasa ekositem penyediaan pangan

\begin{tabular}{lccc}
\hline \multicolumn{1}{c}{ Parameter } & Bobot & Skor & Nilai \\
\hline Kemiringan Lereng & 0,27 & & 0,089 \\
$0-8 \%$ & & 0,33 & 0,071 \\
$8-15 \%$ & & 0,27 & 0,054 \\
$15-30 \%$ & & 0,20 & 0,036 \\
$30-45 \%$ & & 0,13 & 0,018 \\
$>45 \%$ & 0,20 & 0,07 & \\
Relief & & & 0,101 \\
Dataran & & 0,50 & 0,067 \\
Bukit & & 0,33 & 0,034 \\
Pegunungan & 0,13 & 0,17 & \\
Material & & & 0,067 \\
Alluvium & & 0,50 & 0,045 \\
Piroklastik & 0,33 & 0,022 \\
Bebatuan /Lava & 0,17 & \\
Kedalaman Pelapukan Batuan & 0,07 & & 0,034 \\
Dalam & & 0,50 & 0,022 \\
Sedang & & 0,33 & 0,011 \\
Tinggi & & 0,17 & \\
\hline
\end{tabular}




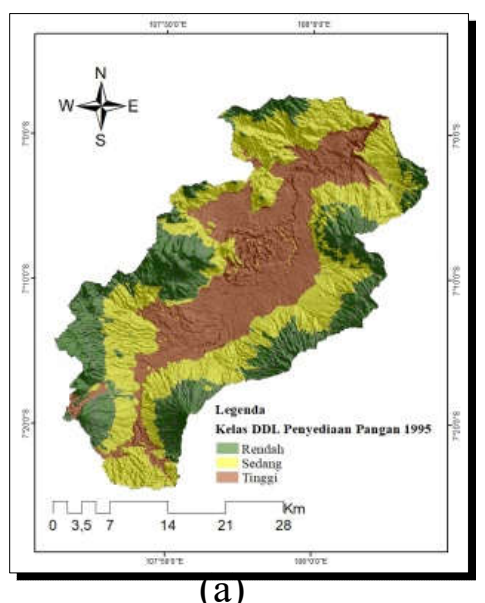

(a)

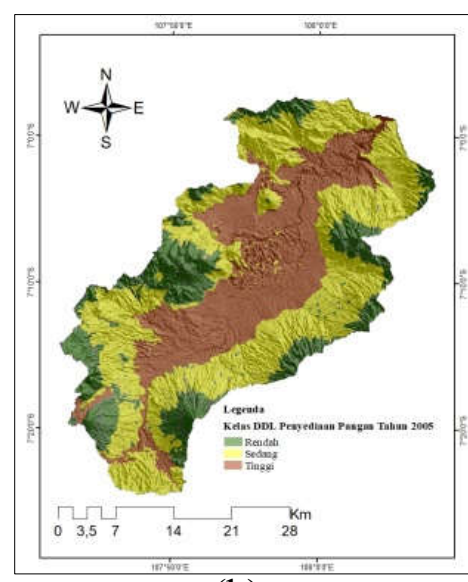

(b)

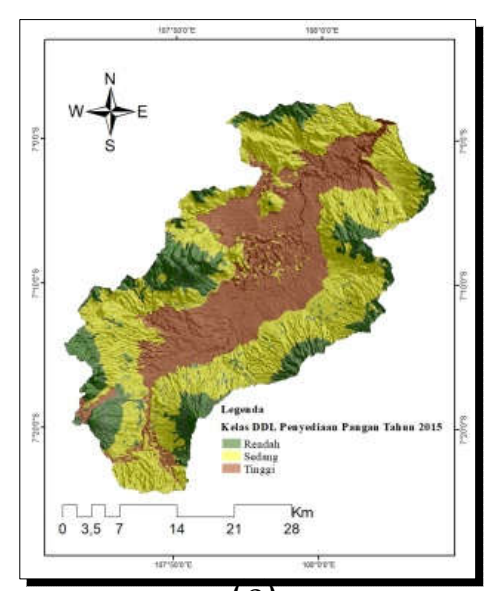

(c)

Gambar 1. Persebaran spasial kelas daya dukung lingkungan berbasis jasa ekosistem untuk penyediaan pangan di DAS Cimanuk Hulu (a) tahun 1995, (b) tahun 2005, dan (c)tahun2015

Analisis Daya Dukung untuk penggunaan lahan dengan bobot

\section{Pengaturan Tata Air}

Indikator yang paling

berpengaruh untuk daya dukung jasa

ekosistem pengaturan tata air adalah
$0,67 \%$, dan faset lahan mendapat bobot 0,33\% (Tabel 5).

Tabel 5. Skor dan bobot daya dukung lingkungan jasa ekosistem pengaturan tata air

\begin{tabular}{lccc}
\hline Parameter & Urutan & $\mathbf{N - R j + 1}$ & Bobot WJ \\
\hline Penggunaan Lahan & 1 & 2 & 0,67 \\
Faset Lahan & 2 & 1 & 0,33 \\
\hline Jumlah & & 3 & 1
\end{tabular}

Berdasarkan hasil analisis untuk daya dukung pengaturan tata air, didapatkan bahwa untuk komponen penggunaan lahan yang paling berpengaruh adalah hutan. (Tabel 6). Adapun (Tabel 7) berikut menyajikan hasil penilaian terhadap komponenkomponen faset lahan, terdiri atas kemiringan lereng, relief, material, kedalaman pelapukan batuan. Nilai yang tinggi memperlihatkan jasa yang tinggi untuk pengaturan tata air. 
Tabel 6. Bobot, Skor dan Nilai daya dukung jasa ekositem pengaturan tata air

\begin{tabular}{|c|c|c|c|}
\hline Parameter & Bobot & Słror & Nilai \\
\hline Penggunaan Lahan & 0,67 & & \\
\hline Hutar & & $0,20^{-}$ & 0,133 \\
\hline Badan Air & & 0,18 & 0,119 \\
\hline Kebun Carupuran & & 0,16 & 0,104 \\
\hline Perkebunan & & 0,13 & 0,089 \\
\hline Sawah & & 0,11 & 0,074 \\
\hline Padang Rumput & & 0,09 & 0,059 \\
\hline Tegalan & & 0,07 & 0,044 \\
\hline Lahan Terbuka & & 0,04 & 0,030 \\
\hline Permukiman & & 0,02 & 0,015 \\
\hline Faset Lahan & 0,33 & & \\
\hline Keriringan Lereng (\%) & & $0,40^{-}$ & 0,133 \\
\hline Material & & $0,30^{\circ}$ & 0,100 \\
\hline Relief & & $0,20^{\circ}$ & 0,067 \\
\hline Kedalaman Tanah & & $0,10^{\circ}$ & 0,033 \\
\hline Jumlah & 1 & & \\
\hline
\end{tabular}

\section{Perubahan Daya Dukung} Lingkungan untuk Pengaturan Tata Air

Di dalam Gambar 3a (tahun 1995) terlihat bahwa wilayah yang memiliki daya dukung tinggi untuk pengaturan tata air menyebar pada bentanglahan dataran fluvio-vulkanik, lembah, dan pegunungan vulkanik dengan jenis penggunaan lahan dominan berupa hutan dan kebun campuran Sementara itu wilayah yang memiliki daya dukung sedang tersebar secara dominan pada bentanglahan lereng bawah kerucut vulkanik dengan jenis penggunaan lahan perkebunan, dan sedikit tegalan. Wilayah yang memiliki daya dukung rendah tersebar pada lereng tengah kerucut vulkanik Papandayan dan kompleks Gunungapi Guntur dengan jenis penggunaan lahan terbuka. Untuk Gambar 3b (tahun 2005), pola persebaran kelas daya dukung terlihat mirip dengan tahun 1995 sebelumnya, namun luasannya yang berubah. Daya dukung tinggi yang tersebar di dataran fluviovulkanik dan lereng atas kerucut vulkanik denudasional berkurang luasannya sebesar 23.984 ha atau $40 \%$. Sementara itu untuk daya dukung kelas sedang mengalami penaikan luas sebesar11.886 ha atau $29 \%$, sedangkan untuk daya dukung kelas rendah mengalami peningkatan seluas 12.208 ha atau $78 \%$. Untuk Gambar 3c (tahun 2015), pola persebaran daya dukung juga masih mirip dengan tahun-tahun sebelumnya, hanya luasannya yang berubah. Dalam hal ini daya dukung kelas tinggi terlihat semakin berkurang luasannya, yaitu sebesar 1.812 ha atau 5\%, sedangkan untuk daya dukung kelas rendah mengalami peningkatan luasan 3.466 ha atau $12 \%$. 
Tabel 7. Bobot, skor, dan nilai daya dukung jasa ekositem pengaturan tata air

\begin{tabular}{lrrr}
\hline Parameter & Bobot & Skor & Nilai \\
\hline Kemiringan lereng & $\mathbf{0 , 1 3}$ & & 0,044 \\
$0-8 \%$ & & 0,33 & 0,036 \\
$8-15 \%$ & & 0,27 & 0,027 \\
$15-30 \%$ & & 0,20 & 0,018 \\
$30-45 \%$ & & 0,13 & 0,009 \\
$>45 \%$ & $\mathbf{0 , 1 0}$ & 0,07 & 0,050 \\
material & & & 0,033 \\
alluvium & & 0,50 & 0,017 \\
piroklastik & $\mathbf{0 , 0 7}$ & 0,33 & 0,033 \\
bebatuan /lava & 0,17 & 0,022 \\
relief & & & 0,011 \\
Dataran & & 0,50 & 0,017 \\
pegunungan & 0,33 & 0,011 \\
Bukit & $\mathbf{0 , 0 3}$ & 0,17 & 0,006 \\
kedalaman pelapukan & & 0,50 & \\
dalam & & 0,33 & 0,17 \\
sedang & & & \\
dangkal & 1 & & \\
\hline Jumlah & & & \\
\hline
\end{tabular}

Hasil daya dukung pengaturan termasuk didalam konsistensi, atau jasa ekosistem penyediaan pangan jawaban berada pada nilai 0,10 atau dan pengaturan dalam hal ini bahwa $\quad 10 \%$ semua jawaban dari expert sudah

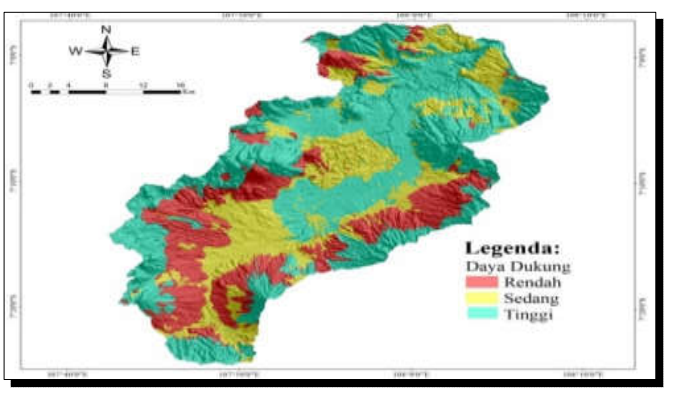

(a)

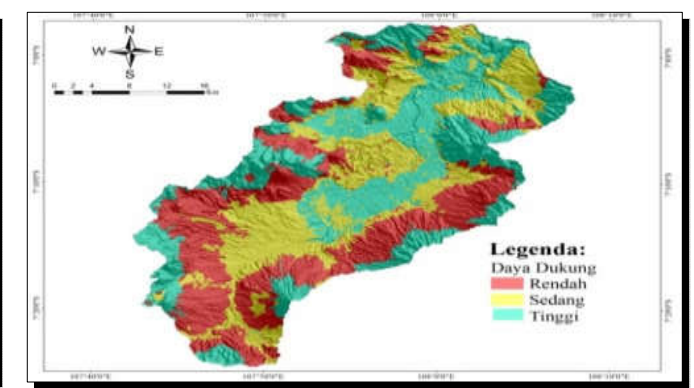

(b)

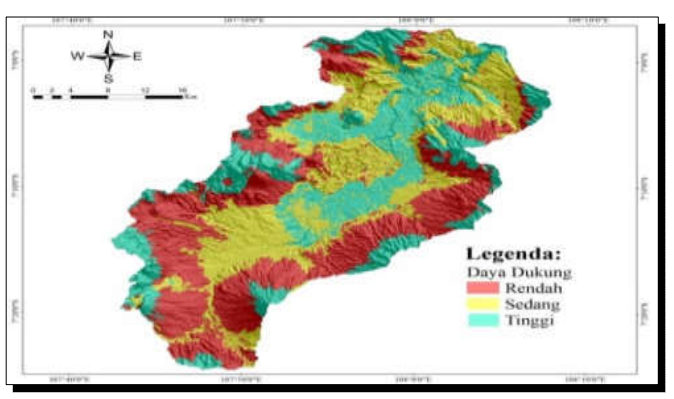

(c)

Gambar 2. Persebaran spasial daya dukung berbasis jasa ekosistem untuk pengaturan tata air di DAS Cimanuk Hulu (a) tahun 1995,(b) tahun 2005, dan (c) tahun 2015 


\section{Bahaya Kerusakan Fungsi DAS}

Pengertian bahaya dalam penelitian ini adalah kemungkinan kejadian di masa depan, baik disebabkan oleh kejadian fisik alami ataupun oleh manusia, yang mempunyai efek merugikan pada elemen yang rentan dan terpapar (Cordona et al. 2012). Adapun yang dimaksud dengan kerusakan fungsi $D A S$ adalah menurunnya fungsi DAS yang tidak seperti yang diharapkan dalam sistem pengelolaannya. Menurut kementerian pekerjaan umum (2010) fungsi DAS Cimanuk Hulu telah ditetapkan sebagai daerah tangkapan air(recharge areas) atau sebagai daerah konservasi air. Dengan demikian, target utama yang ingin dicapai dalam pengelolaan adalah ketersediaan air mencukupi sepanjang tahun di dalam DAS tanpa melahirkan suatu bencana baik di hulu maupun di hilir.

Dalam penelitian ini alat yang digunakan untuk menilai kerusakan fungsi DAS adalah nilai daya dukung DAS untuk pengaturan tata air yang dilihat dari kronologi waktu yang telah berjalan (1995, 2005, dan 2015). Berdasarkan hasil analisis yang telah diuraiankan di atas, terlihat bahwa pola daya dukung untuk penyediaan pangan di daerah penelitian cenderung meningkat seperti yang digambarkan pada peningkatan luas daya dukung kelas tinggi dan menurunnya daya dukung kelas sedang dan rendah. Hal ini mengindikasikan bahwa kondisi bentanglahan di DAS Cimanuk Hulu sangat berpotensi besar (subur) untuk pengembangan pertanian di sektor pangan. Namun demikian meningkatnya penyediaan pangan ini ternyata telah berdampak negatif terhadap aspek lain, yaitu daya dukung untuk tata air. Hal ini tercermin dari menurunnya daya dukung kelas tinggi dan sebaliknya menaiknya daya dukung kelas sedang dan rendah (Gambar 4).

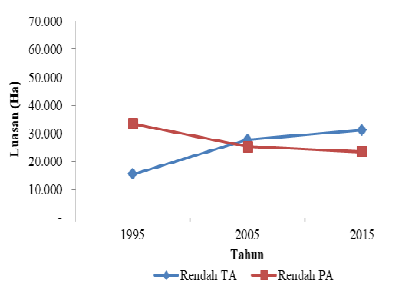

(a)

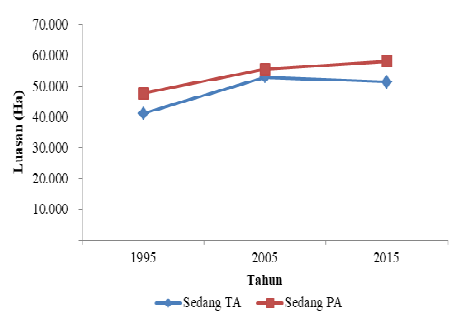

(b)

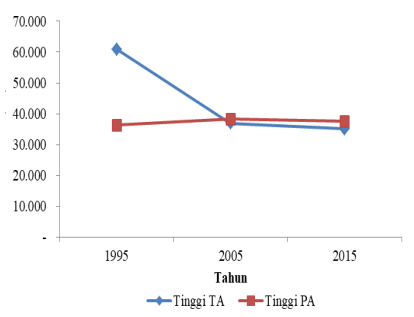

(c)

Keterangan TA = Tata Air; PA = Pangan

Gambar 3. Trend perubahan daya dukung untuk penyediaan pangan dan pengaturan tata air (a) kelas rendah, (b) kelas sedang, dan (c) kelas tinggi 
Berdasarkan kecenderungan tersebut di atas, dapat disimpulkan bahwa pengembangan lahan pertanian pangan di daerah penelitian, setidaknya dari tahun 1995 hingga 2015, telah berdampak buruk dengan menurunnya daya dukung tata air DAS hulu, atau dengan kata lain telah merusak fungsi DAS sebagai daerah tangkapan air (Gambar 5). Dengan demikian kejadian banjir bandang yang menimpa Kota Garut pada September 2016 dan tahun-tahun sebelumnya dapat difahami dari kecenderungan penurunan daya dukung untuk pengaturan tata air ini.

\section{KESIMPULAN}

Daya dukung jasa ekosistem untuk penyediaan pangan di DAS Cimanuk Hulu sangat tinggi tercermin dari meningkatnya luasan daya dukung kelas tinggi dari tahun 1995 hingga 2015 dan menurunnnya kelas sedang dan rendah. Dalam periode waktu yang sama, daya dukung jasa ekosistem untuk pengtauran tata air mengalami penurunan, terlihat dari menurunnya luas daya dukung kelas tinggi dan meningkatnya luasan kelas sedang dan rendah. Kecenderungan menurunnya daya dukung lingkungan untuk tata air mencerminkan adanya bahaya kerusakan fungsi DAS Cimanuk Hulu sebagai wilayah konservasi air. Penyebab utama adalah semakin meluasnya lahan pertanian pangan dan menurunnya luas lahan bervegetasi rapat atau hutan
Diperlukan upaya sungguhsungguh dari pemerintah dan masyarakat untuk memulihkan daya dukung pengaturan tata air DAS Cimanuk Hulu berupa pengendalian penggunaan lahan atau tata ruang. Selain itu pembuatan lubang resapan biopori atau sumur resapan pada daerah permukiman sangat penting dilakukan untuk menampung air hujan sehingga dapat meningkatkan resapan dan mengurangi banjir.

\section{DAFTAR PUSTAKA}

Abdurrahman. 2009. Pengaruh Luas Pola Penggunaan Lahan Dan Kondisi Fisik Lingkungan Terhadap Debit Air Dan Sedimentasi Pada Beberapa Daerah Tangkapan Air (Catshment Area) Di Sub DAS Cimanuk Hulu Jawa Barat. J. Agroland 16 (3) 224-230.

Adi RN, Savitri E. 2017. Daya dukung DAS Brantas berdasarkan evaluasi kriteria tata air. Prosiding Seminar Nasional Geografi UMS 2017.

Cordona OD, Aalst, Birkmann, Fordham, Gregor, Perez, Pulwarty, Schipper, Sinh, 2012. Determinants of risk: exposure and vulnerability. Cambridge University Press, Cambraight, UK and New York, NY,USA.

Duitasari. 2017. Penggunaan Lahan Di DAS Cimanuk Hulu:Perubahan Dan Keterkaitannya Dengan Faset Lahan [skripsi]. Bogor (ID): Institut Pertanian Bogor. 
Hein L, Koppen VK, Groot RSD, Lerland EC. An Spatial Scale Stakeholders And The Valuation Of Ecosytem Servises. J. elsever 57(2) 2009-228.

Hidayat Y, Murtilaksono K, Wahjunie ED, Panuju DR. 2013. Pencirian Debit Aliran Sungai Citarum Hulu (The Characteristics Of River Discharge Of Citarum Hulu). J. Ilmu Pertanian Indonesia.18(2) 109-114.

Hidayat Y, Sinukaban N, Pawitan H, Tarigan SD.2008. Dampak Perubahan Hutan Terhadap Aliran Permukaan Dan Erosi Di DAS Nopu Hulu, Sulawesi Tengah. J. Tanah.13 (1) 59-65.

Ikqra. 2012. Studi Geomorfologi Pulau

Ternate dan Penilaian Resiko Longsor

[Tesis]. Bogor (ID) : Institut Pertanian Bogor.

Junaidi E, Tarigan SD. 2011. Pengaruh Hutan Dalam Pengaturan Tata Air dan Proses Sedimentasi Daerah Aliran Sungai (DAS). J. Penelitian Hutan Dan Konservasi Alam. 8 (2)155-176.

Menteri Pekerjaan Umum. 2010. Keputusan menteri No267 tentang Pola pengelolaan sumberdaya air wilayah sungai Cimanuk-Cisanggarung.

Nugraha I. 2016 September 21. Detikdetik menjelang banjir mengerikan di Garut. Kompas.com. Assifa F, editor. [diunduh 2017 Agustus 28]. Tersedia pada: http://regional.kompas.com/rea d/2016/09/21/15191261/detik detik.menjelang.banjir.mengerik an.di.garut.

Rahman A. 2016. Analisis aliran pada Daerah Aliran Sungai Cimanuk (Studi Kasus Cimanuk-Bojong loa Garut) J. Konstruksi. 14 (1) 91-100.

Saaty TL. 1990. The analytic hierarchy process, paperback edition, RWS Publications, Pittsburgh. First appeared 1980, McGraw Hill.New York.

Susetyaningsih A. 2012. Pengaturan Penggunaan Lahan Didaerah Hulu Das Cimanuk Sebagai Upaya Optimalisasi Pemanfaatan Sumber Daya Air. J. konstruksi.18.

Tjahjono B, Barus B, Duitasari, Sulaiman D. 2016. Hubungan perubahan penggunaan lahan dan debit sungai di DAS Cimanuk. Pusat studi bencanaLPPM IPB.

Wiguna T. 2017. Pemetaan faset lahan dan lahan kritis di daerah aliran sungai

(DAS) Cimanuk Hulu [Skripsi]. Bogor (ID): Institut Pertanian Bogor. 